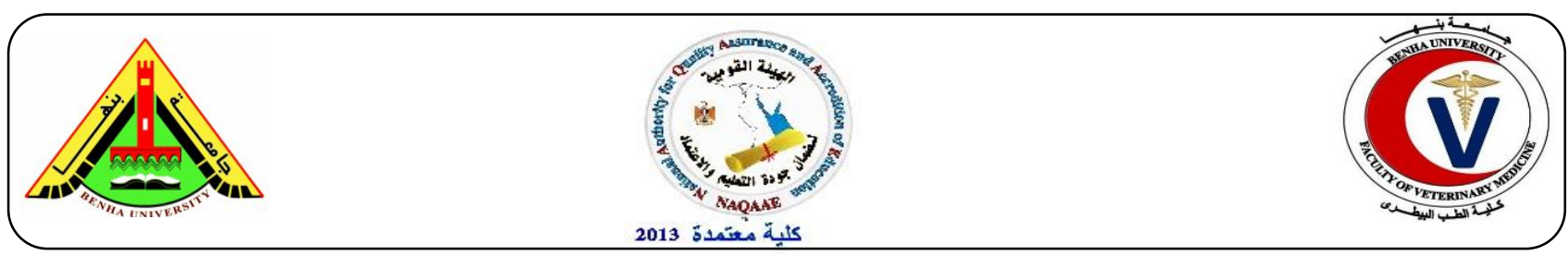

\title{
Chrysin regulates NAD(P)H:quinoneoxidoreductase 1 and inflammatory mediators in rats exposed to smoking and thioacetamide
}

\author{
Omayma A.R. Abozaid ${ }^{1}$, Sawsan M. El-Sonbaty ${ }^{2}$, Ateff B. Ghareeb ${ }^{1}$ \\ ${ }^{\text {I} B i o c h e m i s t r y ~ D e p a r t m e n t . ~ F a c u l t y ~ o f ~ V e t e r i n a r y ~ M e d i c i n e, ~ B e n h a ~ U n i v e r s i t y ~}$ \\ ${ }^{2}$ Radiation microbiology Department, National Center for Radiation Research and Technology, Atomic \\ Energy Authority, Cairo, Egypt.
}

\section{A B S T R A C T}

Tobacco smoking and hepatic damage causes oxidative stress in humans and underlay numerous chronic degenerative diseases. Heavy smoking yields toxins which induce necroinflammation and increase the severity of hepatic lesions. Accordingly, the main object of this study to investigate the effect of chrysin against thioacetamide (TAA)-induced liver injury in rats exposed to tobacco smoke in combination. The study was carried out by investigating the oxidative stress biomarkers (glutathione peroxidase, SOD, catalase, paroxynase-1 and NAD (P) H: quinoneoxidoreductase 1 activities), inflammatory markers (IL-6 and IL-8 levels and gene expressions of NF- $\kappa$ B and VEGF) as well as histopathogical examination. It was found a significant reduction in activities of antioxidant enzymes concomitant with cytokines elevation; (IL-6 and IL-8) in rats exposed to tobacco smoke in combination with (TAA) treatment compared with normal control. Additionally, the transcript levels of (NF- $\kappa \mathrm{B}$ and VEGF) genes were significantly higher in the rats exposed to tobacco smoke in combination with (TAA) treatment compared with normal control. However, treatment with chrysin, the levels of these parameters were significantly decreased which demonstrates the ameliorative effect of chrysin against (TAA) induced liver injury in rats exposed to tobacco smoke in combination. Histological investigations revealed that chrysin gave more preventive effect against thioacetamide (TAA)-induced liver injury in rats exposed to tobacco smoke. In conclusion, chrysin modulated the damage induced by exposure to tobacco smoking and hepatic disease.

Keywords: Thioacetamide (TAA), glutathione peroxidase (GPx), superoxide dismutase (SOD), catalase (CAT), paroxynase -1, NAD P H oxidase, quinoneoxidoreductase 1 activities, interleukin 6 (IL-6), interleukin 8 ( IL-8), nuclear factor-kappa B (NF- $\mathrm{B})$, vascular endothelial growth factor (VEGF)

(http://www.bvmi.bu.edu.eg)(BVMJ-34(1): 277-288, 2018)

\section{INTRODUCTION}

The use of tobacco products is the leading preventable cause of death in the world today, resulting in nearly six million deaths annually and assisting in the manifestation of many other diseases (World Health Organization, 2013). In addition, the economic damages caused by tobacco smoking in the US alone over the past four 
decades could exceed $\$ 7$ trillion USD (extrapolated from CDC reported data, unpublished).

Smoking considers being wide public health problem, which reached today to the level of global epidemical. It is a risk factor for variety of disease (cardiovascular disease, stroke, chronic pulmonary disease, Alzheimer's disease, Parkinson's disease) (Gboyega et al., 2013). About more than5 million people die from smoking related illnesses, as the report of World Health Organization [World Health Organization, 2002)], this number will be doubled by 2025.Smoking causes a variety of adverse effects on organs that have no direct contact with the smoke itself such as the liver. It induces three major adverse effects on the liver: direct or indirect toxic effects, immunological effects and oncogenic effects. Smoking yields chemical substances with cytotoxic potential which increase

Necroinflammation and fibrosis, In addition, smoking increases the production of pro-inflammatory cytokines (IL-1, IL-6 and $\mathrm{TNF}-\alpha$ ) that would be involved in liver cell injury. It contributes to the development of secondary polycythemia and in turn to increased red cell mass and turnover which might be a contributing factor to secondary iron overload disease promoting oxidative stress of hepatocytes. Increased red cell mass and turnover is associated with increased purine catabolism which promotes excessive production of uric acid. Smoking affects both cell-mediated and humeral immune responses by blocking lymphocyte proliferation and inducing apoptosis of lymphocytes. Smoking also increases serum and hepatic iron which induce oxidative stress and lipid peroxidation that lead to activation of stellate cells and development of fibrosis. Smoking yields chemicals with oncogenic potential that increase the risk of hepatocellular carcinoma
(HCC) in patients with viral hepatitis and are independent of viral infection as well. Tobacco smoking has been associated with suppression of p53 (tumor suppressor gene). In addition, smoking causes suppression of Tcell responses and is associated with decreased surveillance for tumor cells. Moreover, it has been reported that heavy smoking affects the sustained virological response to interferon (IFN) therapy in hepatitis $\mathrm{C}$ patients which can be improved by repeated phlebotomy. Smoker's syndrome is a clinico-pathological condition where patients complain of episodes of facial fleshing, warmth of the palms and soles of feet, throbbing headache, fullness in the head, dizziness, lethargy, prickling sensation, pruritus and arthralgia (El-Zayadi, 2006).

Tobacco smoking is the inhalation of smoke from burned dried or cured leavesof the tobacco plant, most often in the form of a cigarette. Cigarette smoke contains a toxic collection of more than 4000 chemicals including nicotine, which combined give rise to addictive stimulant and euphoriant properties. According to the World health Organization, about one third of the world's male population smokes tobacco and cigarette smoking (CS) killed 100 million people worldwide in the 20th century. Therefore, CS is considered a major cause of preventable morbidity and mortality worldwide (Heet al. 2005; Pham et al. 2007). Hepatologists have traditionally paid scant attention to the deleterious effects of CS. (Bataller, 2006). This reflects the fact that smoking per se does not appear to cause liver injury and therefore is not considered a causative agent for chronic liver diseases (Whitehead et al. 1996). However, there is increasing evidence that CS may negatively impact the incidence, severity and clinical course of many types of chronic liver diseases including hepatocellular carcinoma (HCC) (El-Zayadi, 2006). 
Chrysin, a natural flavonoid compound, has been reported to have antioxidant properties via free radical scavenging (Sathiavelu et al., 2009) and upregulation of antioxidant defense mechanisms (Sultana et al.,2012). In addition, chrysin could decrease lipid peroxidation level induced by various oxidants (Anand $e t$ al., 2012). Moreover, chrysin has been reported to have potent anti-inflammatory effects both in vitro and in vivo mainly via inhibiting several cytokines including Tumor Necrosis Factor- $\alpha$ (TNF- $\alpha$ ), interlukin-6 (IL6 ), interlukin-1 $\beta$ (IL-1 $\beta$ ) and nitric oxide (NO) (Cho et al., 2004; Harasstani et al.,2010). In this regard, inhibition of such inflammatory mediators could be attributed to suppression of (NF- B), a transcription factor regulating the expression of proinflammatory mediators. This occurs because chrysin was found to block its activation in vitro (Shin et al., 2009; Ha et al., 2010) and in vivo(Shin et al., 2009; Rehman et al., 2013) where it suppressed the phosphorylation of inhibitor of kappa B(I B) preventing its degradation and thus suspended the nuclear translocation of (NF- B). Finally, chrysin was reported to exert several biological properties such as antioxidant, anti-inflammatory, anti-apoptotic (Sultana et al., 2012) and hepatoprotective effects (Ciftciet al., 2012a). Based on the above facts and properties of the Chrysin, the study was designed to check the protective efficacy of Chrysin against nicotine-induced hepatotoxicity targeting oxidative stress and apoptosis.

\section{Materials and methods}

\subsection{Drugs and Chemicals}

Thioacetamide was purchased from Sigma Chemical Co. (St.Louis, MO, USA) in the form of powder. Chrysin was purchased from Sigma-Aldrich Chemical Company, (St. Louis, MO, USA). Chrysin was suspended in distilled water. Other chemicals were of the highest grade commercially available.

\subsection{Study population}

A total 35 adult male Wistar albino rats (8-10 weeks, 100-120 gm) were purchased from the animal house, Faculty of Medicine, Zagazig University, Egypt. Rats were kept in ventilated stainless steel cages in a clean room at a controlled temperature (20$25^{\circ} \mathrm{C}$ ) and illumination (12 h light/dark). They were fed a standard pellet diet and water adlibitum. This diet was designed by the National Research Institute for Nutrition, Giza, according to the National Nutrition Database for Standard Reference. The animals were left for one week for acclimatization.

\subsection{Animal treatments}

Cleopatra cigarettes (king size, Eastern Company, Egypt) were obtained from Hyper One Mall (the 10th of Ramadan, ElSharqia, Egypt). Each cigarette contains $1 \mathrm{mg}$ of nicotine and $15 \mathrm{mg}$ of tar.

\subsection{Emphysematous model}

Our smoking inhalation system device was based on the work of Cendon et al. (1997) and Kozma et al. (2014). The rats were exposed to the smoke of 10 cigarettes/three times/day for 4 weeks. Each exposure period was one hour (from 9:00 a.m. to 10:00 a.m.; from12:00 p.m. to 1:00 p.m.; from 7:00 p.m. to 8:00 p.m.). During each exposure period, the animals were exposed to smoke for $10 \mathrm{~min}$, followed by $5 \mathrm{~min}$ of exposure to fresh room air to avoid hypoxia.

\subsection{Experimental design}

The rats were randomly divided into the following groups; Group 1 (Control): Healthy rats were kept as control. Group 2 (Chry): Rats received chrysin orally at the dose of $25 \mathrm{mg} / \mathrm{kg}$ b.wt. once daily for one month (Pushpavalli et al., 2010). Group 3 (Cig. + TAA): Rats were received $250 \mathrm{mg} / \mathrm{kg}$, i.p. three times a week for 6 weeks then exposed tobacco smoke for 2 months .Group 4 (Cig. + TAA +Chry): Rats were received 
$250 \mathrm{mg} / \mathrm{kg}$, i.p. three times a week for 6 weeks then exposed tobacco smoke for 2 months, after the exposure to tobacco smoke, rats received chrysin as in group 2.

2.6. Tissue preparation for histological liver evaluation and homogenate

The rats were euthanized with an intraperitoneal injection of $0.2 \mathrm{ml}$ of 260 $\mathrm{mg} / \mathrm{ml}$ sodium pentobarbital after 4 weeks post-last treatment. Then, instillation of fixative (10\% neutral buffered formalin, $\mathrm{pH}$ 7.4) was carried out under a constant pressure of $20 \mathrm{cmH}_{2} \mathrm{O} .1 \mathrm{gm}$ of the liver were dissected, immersed in fixative and processed for paraffin block. Then, $5 \mu \mathrm{m}$ thick sections were cut, deparaffinized, rehydrated and stained with hematoxylin and eosin (H\&E) (Bancroft and Layton, 2012). The rest of the liver was cut into small pieces and subsequently homogenized with $10 \mathrm{mM}$ potassium phosphate buffer ( $\mathrm{pH}$ 7.4) containing 0.1 mMEthyleneDiamine Tetra Acetic acid (Sigma, St. Louis MO), $0.1 \mathrm{mM}$ phenyl-methanesulfonyl

fluoride

(NacalaiTesque, Kyoto, Japan), $1 \mu$ Mpepstatin A (Peptide Institute, Osaka, Japan), and $2 \mu \mathrm{M}$ leupeptin(Peptide Institute). The homogenates were then centrifuged at $105,000 \times \mathrm{g}$ for $1 \mathrm{~h}$ at $4 \circ \mathrm{C}$. Thereafter, the supernatants were stored at $-80{ }^{\circ} \mathrm{C}$ until used.

\subsection{Assay of antioxidant biomarkers}

To demonstrate systemic liver redox, activities of antioxidant enzymes; superoxide dismutase (SOD), glutathione peroxidase (GPx),Paraoxonase (PON-1) and catalase (CAT) were determined. SOD (U/g protein, EC 1.15.1.1) activity was determined based on the method of Sun et al. (1988).CAT (U/g protein; EC 1.11.1.6) activity was determined with respect to Aebi (1984) method. Glutathione peroxidase (GPx) activity was determined based on the method of Rotruck et al. (1973) method [E.C. 1.11.1.9]. PON-1 (U/mg tissue) activity was determined according to the method of Beltowski et al. 2005.

\subsection{Real-time PCR}

The liver was disrupted using a motorized pestle and mortar, and total RNA was extracted using an RNeasy mini kit (Qiagen, cat. number. 74104, Germany). RNA concentration was determined using a Spectrophotometer (Thermo scientific, USA). RNA (500 ng) was reverse transcribed to cDNA using Quantitect Reverse Transcription Kit (Qiagen, cat. number. 205310, Germany). The cDNA was used as template for real-time PCR using Quanti Fast SYBR Green PCR Kit (Qiagen, cat. number. 204052, Germany). The sequences of the primers for NF- $\kappa$ B were $F$ : 5'-ACAACCCCTTCCAAGTTCCCT-3'

(sense) and R: 5'TGGTCCCGTGAAATACACCT-3' (antisense). The sequences of the primers for VEGF were F: 5'TGCACCCACGACAGAAGGGGA-3' (sense) and R: 5'TCACCGCCTTGGCTTGTCACAT-3' (antisense). The sequences of the primers for NADPH F: 5'-CAGCGGCTCCATGTACT-3' (sense) and $\mathrm{R}$ : 5'GACCTGGAAGCCACAGAAG-3' (antisense). $\beta$-actin (housekeeping gene) was used as an internal control to ensure equal loading. All the experiments were performed according to the manufacturer's protocols. All samples were loaded into the qRT-PCR system (Light Cycler 480 II, Roche, USA) and run in triplicate using the following cycling parameters: $95{ }^{\circ} \mathrm{C}$ for $5 \mathrm{~min}$ for PCR initial heat activation; 40 repetitions of cycling: $95{ }^{\circ} \mathrm{C}$ for $10 \mathrm{~s}$ for denaturation and combined annealing/extension at $60{ }^{\circ} \mathrm{C}$ for 30 s. Data analysis was carried out using the 2dCT method.

\subsection{Cytokine Analysis.}

Cytokines, IL-6 and IL-8 that are prominent cytokines involved in inflammation were measured in serum using 
Rat interleukin-6 ELISA kit (Bender Medsystem, Burlingham, CA, USA (Cat no BMS625) and Rat interleukin-8 ELISA kit ( My BioSource, Southern California, San Diego (USA). (Cat no MBS025179).

2.9. Statistical analysis:

Statistical analysis of differences between means was carried out using oneway analysis of variance (ANOVA). In case of a significant F-ratio, post hoc least significant difference (LSD) test for multiple comparisons was used to evaluate the statistical significance between treatment groups at $\mathrm{P}<0.05$ level of significance. All the statistical analysis was done using Statistical Package for Social Science (SPSS) version 20.0 (SPSS Inc., Chicago, IL, USA).

\section{RESULTS}

\subsection{Effect of Chrysin on endogenous antioxidant status}

The changes in the activities of SOD and CAT in liver of control and experimental rats are given in Fig. 1. The hepatic activitiesofGPx and PON-1 are shown in Fig.

2. The activities of SOD, CAT, GPx and
PON-1 were significantly decreased in liver of nicotine-treated group when compared with control. Chrysin co-treatments were significantly increased the activities of SOD, CAT and GPx and PON-1 in liver.

\subsection{Effect of Chrysin on Inflammatory markers}

The changes in the levels of IL-6 and IL-8 in liver of control and experimental rats are given in Fig. 3. The hepatic levels of IL-6 and IL-8 were significantly increased in liver of nicotine-treated group when compared with control. Chrysin co-treatments were significantly decreased the levels of IL-6 and IL-8 in liver.

\subsection{Effect of Chrysin on gene expression of $N Q O 1, N F-\kappa B$ and VEGF.}

The changes in the levels of NQO1, NF- $\kappa B$ and $V E G F$ in liver of control and experimental rats are given in Fig. 4. The hepatic levels of IL-6 and IL-8 were significantly increased in liver of nicotinetreated group when compared with control. Chrysin co-treatments were significantly decreased the levels of IL-6 and IL-8 in liver.

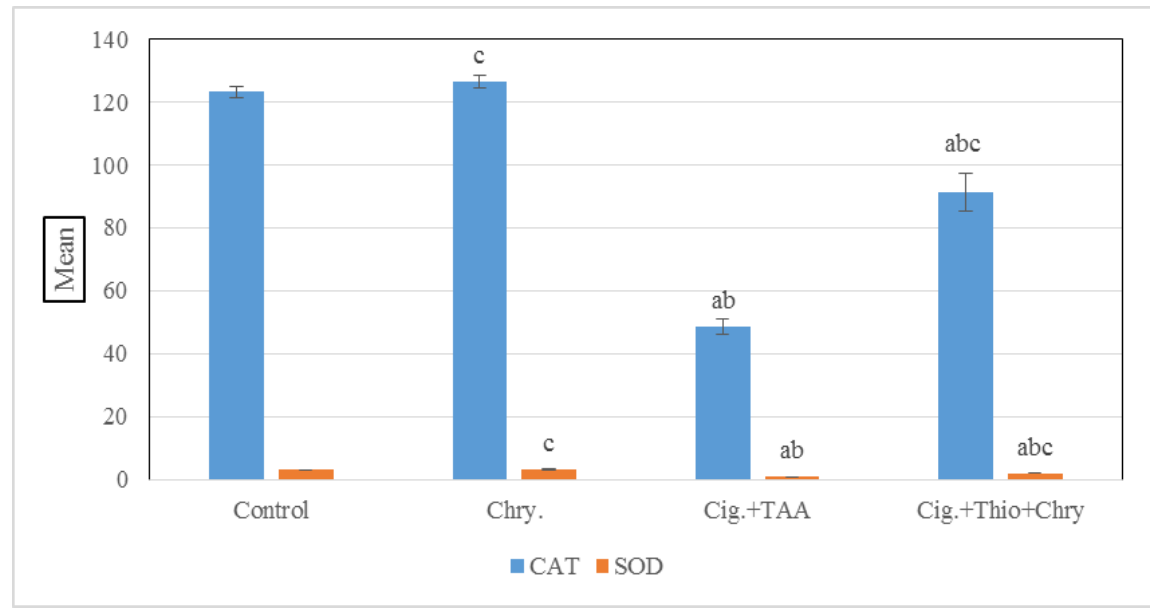

Fig. 1 Changes the CAT and SOD activities in liver after co-administration of Chry. in nicotine treated rats. Data represents mean $\pm \mathrm{SE}, \mathrm{N}=10$. a $\mathrm{p}<0.05$ compared to control, $\mathrm{b} \mathrm{p}<0.05$ compared to chrysin and $\mathrm{c} p<0.05$ compared to Cig. + TAA groups. 


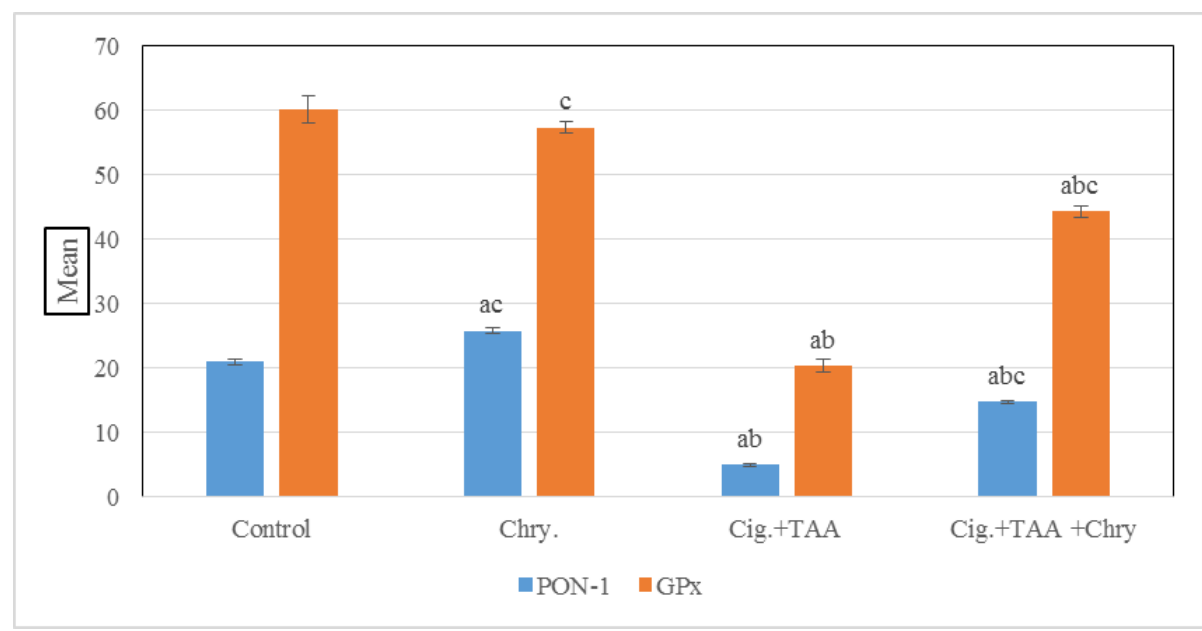

Fig. 2 Changes the GPx activity and PON-1 level in liver after co-administration of Chry. in nicotine treated rats. Data represents mean $\pm \mathrm{SE}, \mathrm{N}=10$. a $\mathrm{p}<0.05$ compared to control, $\mathrm{b} \mathrm{p}<0.05$ compared to chrysin and $\mathrm{c} p<0.05$ compared to Cig. + TAA groups.

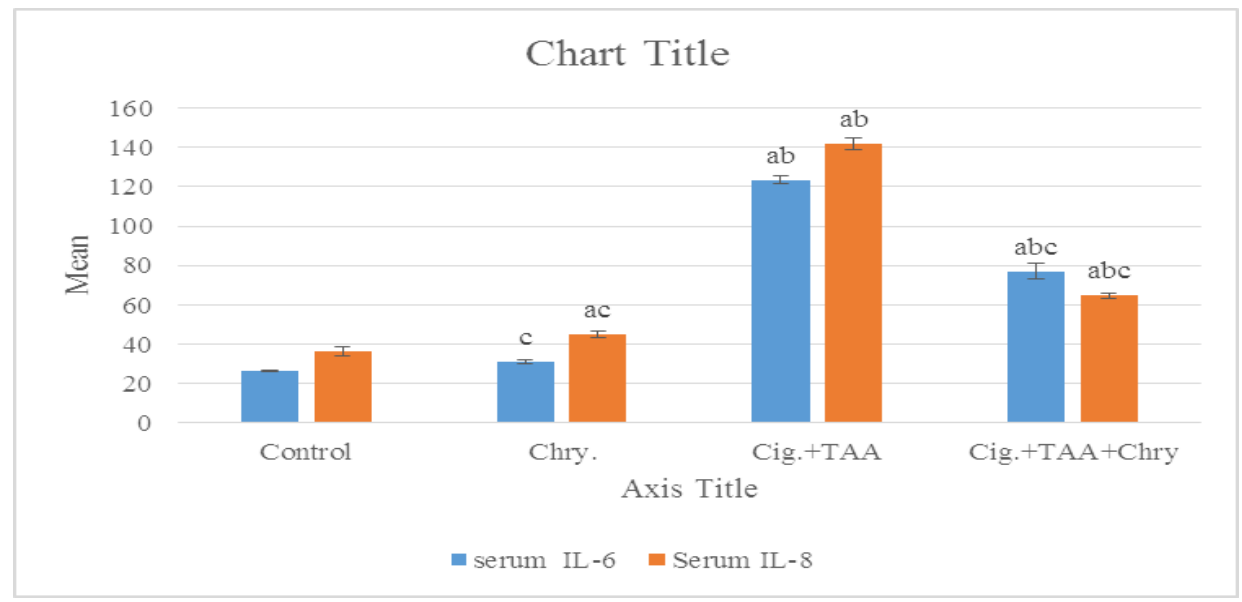

Fig. 3 Changes the IL-6 and IL-8 levels in liver after co-administration of Chry. in nicotine treated rats. Data represents mean $\pm \mathrm{SE}, \mathrm{N}=10$. a $\mathrm{p}<0.05$ compared to control, $\mathrm{b} \mathrm{p}<0.05$ compared to chrysin and $\mathrm{c} p<0.05$ compared to Cig. + TAA groups.

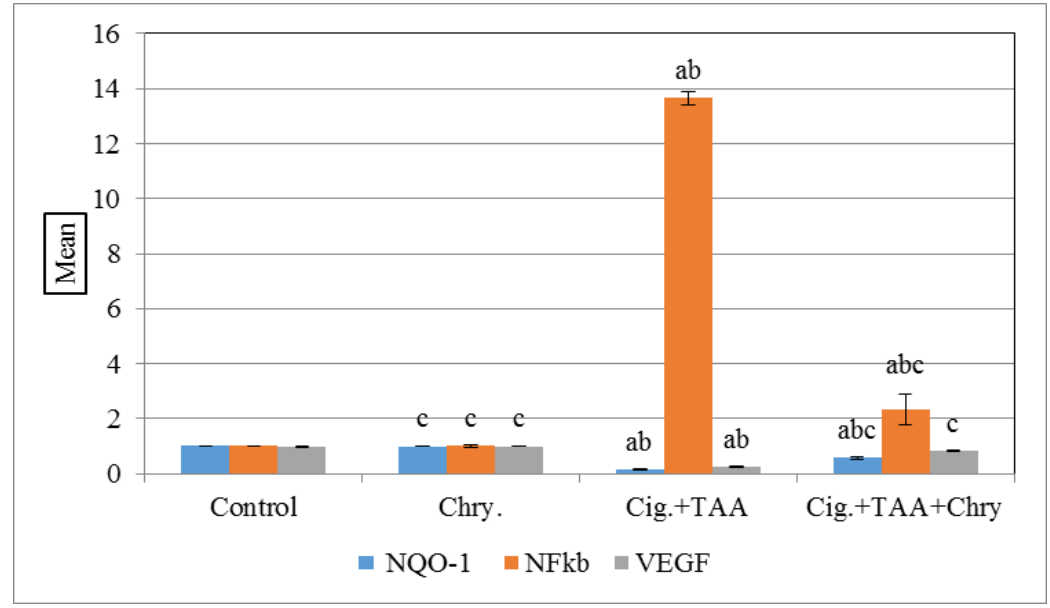

Fig. 4 Changes the NQO1, NF- $\kappa B$ and VEGF gene expressions in liver after co-administration of Chry. in nicotine treated rats. Data represents mean $\pm S E, N=10$. a $p<0.05$ compared to control, $b$ $\mathrm{p}<0.05$ compared to chrysin and $\mathrm{c} p<0.05$ compared to Cig. + TAA groups. 


\section{DISCUSSION}

Cigarette smoking induces three major adverse effects on the liver including immunological, oncogenic and other toxics effects (El-Zayadi, 2006). Nicotine-induced oxidative stress in the liver that was prevented by chrysin in this study. Our study findings showed significantly decreasing in all of CAT, SOD and GXp in cigarette group comparable with control group. We suggested that the decreased in CAT level in smokers group due to accumulation of hydrogen peroxide, which inhibit this enzyme or alter enzymatic conformation. Also this decreased CAT activity could be due to inactivation of CAT by the cross linking or the impairment of nitric oxide (NO) synthase, which can bind reversible to ferric iron and inhibiting afterwards CAT activity (Bogdansk et al. 2003-Yosriet al. 2013).

Our findings about CAT activity were disagreeing with previous results (Omar et al. 2012), which observed increased level of CAT significantly in smokers. Our observation about CAT, SOD and GPx confirm the results of many studies (Anshu and Flora, 2012). Our result disagrees with other studies (Syed Anzar and Alvina, 2016), which observed that about SOD and GXp, which decreased in group of smokers as compared to nonsmokers. The significantly differences of oxidative enzymes levels CAT, SOD and GXp may be due to nicotine increased generation of superoxide anion and hydrogen peroxide, which in turn results in generation of hydroxyl free radicals. Generation of these free radicals have been shown to participate in many toxic reaction and increased production of superoxide and hydrogen peroxide may cause deleterious injury to alveolar macrophages by causing release of proteolytic enzymes (Yildiz, 2004).
Cigarette smoking is a potent inhibitor of PON1 enzymatic activity, making the effectiveness of PON1 in smoker's particularly important (Sentiet al.2003; Nishio and Watanabe, 1997). It was shown that cigarette smoke extract decreases PON1 activity by modifying the free thiol groups of the enzyme. It can be explained by the effects of several of the hundreds of chemical components of tobacco smoke including various reactive aldehydes as well as aromatic hydrocarbons (Nishio and Watanabe, 1997). Moreover, it is important that smoking may increase neutrophil myeloperoxidase activity (Lokeet al. 2012), which has been shown to interact with HDL and to modulate paraoxonase 1 function (Huang et al. 2013).Nicotine increases the cytokines production that could be involved in liver injury (El-Zayadi, 2006).In the present study, proinflammatory cytokines secreted from activatedneutrophils, monocytes and macrophages of nicotine-treatedanimals to remove dead cells and promote tissue repair, as IL-8, and IL-6 have been elevated.Our observation is in coincident with Cromwell et al.(1992) who found increasing the production of $\alpha$-TNF, IL- 1 and IL- 6 within the lung of rats is similar to the effect nicotine. This increase in the levels of cytokines and adhesion molecules results in the activation of neutrophils and macrophages to the lung that can lead to tissue destruction (Wang et al. 2004).

Cigarette constituents (particularly ROS) activate epithelial cell intracellular signaling cascades that lead to inflammatory gene activation [e.g., interleukin-8 or IL-8 and tumor necrosis factor-alpha (TNF $\alpha)$ ] (Churg et al., 2002; Chung, 2005). The secretion of these inflammatory mediators promotes chronic immune cell recruitment and inflammation. 
We have shown in the present study that cigarette smoke reduces both NQO1 and VEGF expression. This result is in coincidence with the researchers who showed that VEGF and VEGFR-2 expression are decreased in emphysematous lungs concomitant with increased endothelial cell apoptosis (Kasahara et al. 2001). VEGF levels are also reduced in the bronchoalveolar lavage fluid of smokers (26). Interestingly, VEGF receptor inhibition leads to the enlargement of the air spaces, increased endothelial cell death, and decreased capillary density, characteristic of emphysema (Jakkula et al. 2000, Kasahara et al. 2000).

Living tissues are endowed with innate antioxidant defense mechanisms, namely CAT, SOD and Gpx. A reduction in the activities of CAT, SOD and Gpx enzymes is associated with the accumulation of highly reactive free radicals, leading to deleterious effects such as loss of integrity and function of cell membranes (Reedy and Lokesh, 1992).Rats that received chrysin along with nicotine in combination with thioacetamide (Group IV), the activities of CAT, SOD and Gpx were significantly higher than in rats that received nicotine in combination with thioacetamide(Group III) rats. These results corroborate previous observations that chrysin treatment increases the activities of antioxidants, such as CAT, SOD and Gpx, in ethanol-induced toxicity in female albino rats (Sathiavelu et al., 2009). Chrysin possibly confers this protective effect by dampening the generation of free radicals that are induced by CCl4.Paraoxonase-1 (PON-1), an enzyme with lactonase and esterase activities, is synthesized mainly by the liver [Leviev et al. 1997, Rodrigo et al. 1997] and it plays a role in the regulation of oxidative stress, fibrosis and hepatic cell apoptosis in chronic liver diseases. [Ferre et al. 2006]. Our result showed that administration of chrysin increased the level of PON-1 and that was agreed with Zhang et al., who proposed that PON-1 over expression provides strong protection against the development of experimental liver disease [Zhang et al. 2008].

The pro-inflammatory cytokines IFN- $\gamma$, IL17A, IL-6, IL-1 $\beta$ and TNF- $\alpha$ contribute to the recruitment, activation and activity of M1 macrophages, leading to ocular inflammation, thus, we evaluated the expression of these cytokines at both the mRNA and protein levels. We observed that chrysin suppressed the levels of IFN- $\gamma$, IL-17A, IL-6, IL-1 $\beta$ and TNF- $\alpha$. Thus, chrysin suppresses intraocular inflammation (Meng X et al. 2017).In the present study, NF- $\kappa \mathrm{B}$ expression was markedly elevated in the Cig+TAAintoxicated animals while chrysin supplementation effectively counteracted this effect. Our results are in accordance with pervious one reporting that downregulating NF- $\kappa \mathrm{B}$ protein expression could be a promising target for protection against DOX cardiotoxicity (Saeed et al. 2015).. Tumor angiogenesis is stimulated by angiogenic growth factors, such as VEGF, basic Fibroblast Growth Factor (bFGF), Transforming Growth Factor (TGF) and Interleukin-8 (IL-8). VEGF and its receptors have been described as the fundamental regulators of angiogenesis and play an important role in tumor progression (Fang et al., 2005). Generally, the important effects of chrysin in cellular processes can be concluded to be (1) the inhibition of HIF-1 $\alpha /$ VEGFregulated angiogenesis via the AKT signaling pathway and (2) the sensitization of TNF $\alpha$ induced cell death via downregulation of NFKB and activation of caspase-8. In addition, (3) chrysin induces also apoptosis via activation of caspase-3, which involves the inactivation of AKT signaling pathway and downregulation of the X-linked Inhibitor of Apoptosis Protein (XIAP) (Samarghandian et al., 2011). 


\section{REFERENCES}

Aebi, H., 1984. Catalase in vitro. Methods Enzymol. 105, 121-126.

Anand, K.V., Mohamed, M.S., Thomas, P.A., Geraldine, P., 2012. Protective role of chrysin against oxidative stress in dgalactose-induced aging in an experimental rat model. Geriatrics and gerontology international. 12, 741-750.

Anshu, J., Flora, S.J.S. 2012. Dose related effects of nicotine on oxidative injury in young, adult and old rats. J Environ Biol 33: 233-238.

Bancroft, J.D., Layton, C., 2012. The Hematoxylins and Eosin. Bancroft's Theory and Practice of Histological Techniques, Expert Consult: Online and Print, 7: Ban-croft's Theory and Practice of Histological Techniques. Elsevier, pp. 173.

Bataller R. Time to ban smoking in patients with chronic liver diseases. Hepatology 2006; 44:1394e6.

Beltowski, J., Jamroz-Wisniewska, A., Borkowska, E., Wojcicka, G. 2005.Differential effect of antioxidant treatment on plasma and tissue paraoxonase activity in hyperleptinemic rats. Pharmacol Res.; 51:523-532.

Bogdansk, J.J., Korneti, P., Todorova, B. 2003. Erythrocyte superoxide dismutase, glutathione peroxidase and catalase activities in healthy male subjects in republic of Macedonia. Bratisl Lek Listy 104: 108-114.

Cendon, S., Battlehner, C., Lorenzi-Filho, G., Dohlnikoff, M., Pereira, P., Conceic, ão, G.,Beppu, O., Saldiva, P., 1997.
Pulmonary emphysema induced by passive smoking: an experimental study in rats. Braz. J. Med. Biol. Res. 30, 1241-1247.

Cho, H., Yun, C.W., Park, W.K., Kong, J.Y., Kim, K.S., Park, Y., Lee, S., Kim, B.K., 2004.Modulation of the activity of pro-inflammatory enzymes, COX-2 and iNOS, by chrysin derivatives. The official journal of the Italian Pharmacological Society 49: 37-43.

Chung, K.F. 2005. Inflammatory mediators in chronic obstructive pulmonary disease. Curr Drug Targets Inflamm Allergy 4:619-625.

Churg, A., Dai, J., Tai, H., Xie, C., Wright, J.L. 2002. Tumor necrosis factor-alpha is central to acute cigarette smokeinduced inflammation and connective tissue breakdown. Am J RespirCrit Care Med 166:849-854.

Ciftci, O., Ozdemir, I., Aydin, M., Beytur, A., 2012. Beneficial effects of chrysin on the reproductive system of adult male rats. Andrologia 44: 181-186.

E. Nishio and Y. Watanabe, "Cigarette smoke extract inhibits plasma paraoxonase activity by modification of the enzyme's free thiols," Biochemical and Biophysical Research Communications, vol. 236, no. 2, pp. 289-293, 1997.

El-Zayadi A.R. 2006.Heavy smoking and liver. World J. Gastroenterol. 12(38): 6098-6101.

El-Zayadi AR. Heavy smoking and liver. World J Gastroenterol 2006; 12:6098e101.

Fang, J., Xia, C., Cao, Z. X., Zheng, J. Z., Reed, E. \& Jiang, B. H. 2005. 
Apigenin inhibits VEGF and HIF-1 expression via PI3K/AKT/p70S6K1 and HDM2/p53 pathways. The FASEB Journal, 19(3), 342-353.

Ferre, N., Marsillach, J., Camps, J., Mackness, B., Mackness, M., Riu, F., Coll, B., Tous, M., Joven, J. 2006. Paraoxonase-1 is associated with oxidative stress, fibrosis and FAS expression in chronic liver diseases. $\mathbf{J}$ Hepatol, 45:51-59.

Gboyega, E.A., Adesegun, J.K., Chikezie, U.E. 2013.Tobacco smoking and awareness of smoking cessation products in a University community. $\mathbf{J}$ Public Health Epidemiol 5: 351-356.

Ha, S.K., Moon, E., Kim, S.Y., 2010. Chrysin suppresses LPS-stimulated proinflammatory responses by blocking NF-kappaB and JNK activations in microglia cells. Neuroscience letters; 485: 143-147.

Harasstani, O.A., Moin, S., Tham, C.L., Liew, C.Y., Ismail, N., Rajajendram, R., Harith, H.H., Zakaria, Z.A., 2010. Flavonoid combinations cause synergistic inhibition of proinflammatory mediator secretion from lipopolysaccharide-induced RAW 264. Journal of the European Histamine Research Society. 59: 711721.

He, J., Gu, D., Wu, X. 2005. Major causes of death among men and women in China. N Engl J Med; 353:1124e34.

Jakkula, M., Le Cras, T.D., Gebb, S., Hirth, K.P., Tuder, R.M., Voelkel, N.F., and Abman, S.H. 2000. Inhibition of angiogenesis decreases alveolarization in the developing rat lung. Am J

\section{Physiol Lung Cell MolPhysiol279:} L600-L607.

Kasahara, Y., Tuder, R.M., Cool, C.D., Lynch, D.A., Flores, S.C., and Voelkel, N.F. 2001. Endothelial cell death and decreased expression of vascular endothelial growth factor and vascular endothelial growth factor receptor 2 in emphysema. Am J RespirCrit Care Med 163: 737-744.

Kasahara, Y., Tuder, R.M., TarasevicieneStewart, L., Le Cras, T.D., Abman, S., Hirth, P.K., Waltenberger, J., and Voelkel, N.F. 2000. Inhibition of VEGF receptors causes lung cell apoptosis and emphysema. $J$ Clin Invest 106: 1311-1319.

Koyama, S., Sato, E., Haniuda, M., Numanami, H., Nagai, S., and Izumi, T. 2002. Decreased level of vascular endothelial growth factor in bronchoalveolar lavage fluid of normal smokers and patients with pulmonary fibrosis. Am J Respir Crit Care Med 166: $382-385$.

Kozma, R.d.1.H., Alves, E.M., Barbosa-deOliveira, V.A., Lopes, F.D.T.Q.d., Guardia, R.C.,Buzo, H.V., Faria, C.A.d., Yamashita, C., Cavazzana Junior, M., Frei, F., 2014. A new experimental model of cigarette smoke-induced emphysema in Wistarrats.J.Bras.Pneumol. 40, 46-54.

Leviev, I., Negro, F., James, R.W. 1997. Two alleles of the human paraoxonase gene produce different amounts of mRNA. An explanation for differences in serum concentrations of paraoxonase associated with the (Leu-Met54) polymorphism. Arterioscler Thromb VascBiol, 17:2935-2939. 
Senti, M., Tomás, M., Anglada R., 2003. "Interrelationship of smoking, paraoxonase activity, and leisure time physical activity: a population based study," European Journal of Internal Medicine, vol. 14, no. 3, pp. 178-184, 2003.

Messer, K., Trinidad, D.R., Al-Delaimy, W.K. and Pierce, J.P. 2008. Smoking cessation rates in the United States: a comparison of young adult and older smokers. Am. J. Public Health; 98: 317-322.

Cromwell, O., Hamid, Q., Corrigan, C.J., Barkans, J., Meng, Q., Collins, P.D., Kay, A.B. 1992. Expression and generation of interleukin-8, IL-6 and granulocyte-macrophage colonystimulating factor by bronchial epithelial cells and enhancement by IL1 beta and tumor necrosis factor-alpha, Immunology 77, 330-337.

Omar F.K., Karem H.A., Mohammed B.A., Arwa D., Thomas E. 2012. Acute exposure to water pipe tobacco smoke induces changes in the oxidative and inflammatory markers in mouse lung. $\mathbf{J}$ Inhal Toxicol 24: 667-675.

Pham T.M., Fujino Y., Ide R. 2007. Mortality attributable to cigarette smoking in a cohort study in Japan.Eur J Epidemio 1; 22:599e605.

Reedy A.C. and Lokesh B.R. 1992.Studies on spice principle as an antioxidant in the inhibition of lipid peroxidation of rat liver microsomes. Molecular and Cellular Biochemistry 111: 117-124.

Rehman, M.U., Tahir, M., Khan, A.Q., Khan, R., Lateef, A., Oday-O-HamizaQamar, W., Ali, F., Sultana, S., 2013. Chrysin suppresses renal carcinogenesis via amelioration of hyperproliferation, oxidative stress and inflammation: plausible role of NF- B, Toxicol. Lett. 216, 146-158.

Rodrigo L., Gil F., Hernandez A.F., Marina A., Vazquez J., Pla A.1997. Purification and characterization of paraoxon hydrolase from rat liver. Biochem J, 321(Pt 3):595-601.

Rotruck J.T, Pope A.L, Ganther H.E, Swanson A.B, Hafeman D.G, and Hoekstra W.G, 1973.Science; 179:588590.

Samarghandian, S., Afshari, J. T. \&Davoodi, S. 2011. Chrysin reduces proliferation and induces apoptosis in the human prostate cancer cell line pc-3. Clinics, 66(6), 1073-1079.

Sathiavelu J., Senapathy G.J., Devaraj R. and Namasivayam $\mathrm{N}$. 2009.Hepatoprotective effect of chrysin on prooxidant-antioxidant status during ethanol- induced toxicity in female albino rats. J.Pharm. Pharmacol; 61:809-817.

Sathiavelu J., Senapathy G.J., Devaraj R., and Namasivayam $\mathrm{N}$. 2009.Hepatoprotective effect of chrysin on prooxidant-antioxidant status during ethanol-induced toxicity in female albino rats. Journal of Pharmacy and Pharmacology 61: 809817.

Senthil S., Veerappan R.M., Ramakrishna R., Pugalen Di K.V. 2004. Oxidative stress and antioxidants in patients with cardiogenic shock complicating acute myocardial infraction .ClincChimActa 384: 131-137.

Shin, E.K., Kwon, H.S., Kim, Y.H., Shin, H.K., Kim, J.K., 2009.Chrysin, a 
natural flavone, improves murine inflammatory bowel diseases. Biochemical and biophysical research communications 381, 502-507.

Sultana S, Verma $\mathrm{K}$ and Khan R.2012.Nephroprotective efficacy of chrysin against cisplatin-induced toxicity via attenuation of oxidative stress.J. Pharm. Pharmacol. 64 (6), 872-881.

Sun, Y., Oberley, L.W., Li, Y., 1988. A simple method for clinical assay of superoxide dismutase. Clin. Chem. 34, 497-500.

Syed Anzar AR, Alvina T 2016. The effect of melet deposition on antioxidant enzymes of lens in smokers of Karachi - Pakistan. Asia Pac J Med Toxicol 5: 119- 123.

W. M. Loke, K. M. Lam, W. L. Chong 2012. "Products of 5-lipoxygenase and myeloperoxidase activities are increased in young male cigarette smokers," Free Radical Research, vol. 46, no. 10, pp. 1230-1237.

Whitehead T.P., Robinson D., Allaway S.L., 1996. The effects of cigarette smoking and alcohol consumption on serum liver enzyme activities: a dose-related study in men. Ann ClinBiochem; 33(Pt 6):530e5.

World Health Organization (WHO 2002) He World Health Organization Report 2002 reducing risks, promoting health life. Geneva, Switzerland: World Health Organization.

World Health Organization, 2013. WHO Report on the Global Tobacco Epidemic, 2013: Enforcing Bans on Tobacco Advertising, Promotion and
Sponsorship. (in IRIS). World Health Organization, Geneva.

XiangdaMeng, Sijie Fang, Zhuhong Zhang, Yang Wang, Caiyun You, Jingkai Zhang and Hua Yan 2017.Preventive effect of chrysin on experimental autoimmune uveitis triggered by injection of human IRBP peptide 1-20 in mice. Cellular\& Molecular Immunology 14, 702-711.

Y. Huang, Z. Wu, M. Riwanto 2013. "Myeloperoxidase, paraoxonase-1, and HDL form a functional ternary complex," The Journal of Clinical Investigation, vol. 123, no. 9, pp. 3815-3828.

Y. Wang, L. Wang, X. Ai, J. Zhao, X. Hao, Y. Lu, Z. Qiao 2004. Nicotine could augment adhesion molecule expression in human endothelial cells through macrophages secreting TNF-alpha, IL1beta, Int. Immunopharmacol. 4, 1675 1686.

Yildiz D. 2004. Nicotine, its metabolism and overview of its biological effects. Toxicon 43: 619-632.

Yosri N, Abdelkader $\mathrm{CH}$, Latifa $\mathrm{CH}$, Bruno B, Samia E. 2013. Low erythrocyte catalase enzyme activity is correlated with high serum total homocysteine level in Tunisian patients with Acute myocardial infarction. DiagnPathol 8: 68-74.

Zhang C, Peng W, Jiang X, Chen B, Zhu J, Zang Y, Zhang J, Zhu T, Qin J. 2008. Transgene expression of human PON1 $\mathrm{Q}$ in mice protected the liver against CCl4-induced injury. J Gene Med, 10:94-100. 